\title{
Civic Education in the Age of Trump
}

\author{
Harry Brighouse (University of Wisconsin-Madison)
}

\begin{abstract}
:
Trump's emergence was enabled by numerous factors that have toxified American politics over several decades, and for which both parties bear some responsibility. Among these factors is what we might call the partisanisation of politics.
\end{abstract}

\section{The Situation ${ }^{1}$}

Something has gone terribly wrong. 63 million people were willing to vote for a Presidential candidate who advertised his inexperience in politics and ignorance about policy, who boasted privately of frequently committing criminal assaults and publicly of his tax avoidance skills, who unabashedly courted racist voters, tarred immigrants from Mexico as rapists, drug-dealers and murderers, publicly mocked a reporter for his disability in a way that would make an 8-year old appear immature, and regularly attempted to humiliate female reporters. Since his election (about 14 months ago at the time of writing), he has been just about exactly the President he advertised himself to be: ignorant, dangerous, lazy, ineffective, uninterested in and ignorant about policy and incapable of communicating effectively with other world leaders.

We could see his election as an aberration. He lost the popular vote by a remarkably large margin ${ }^{2}$, and his success in the Republican primary depended on the inability of opposing forces within the party to coalesce around a single candidate. It is unlikely that he would have actually won, had the FBI made different choices about when to release potentially damaging information about his opponent, or without what appears to have been significant attempts by a foreign power to influence the election. And, once he was elected, senior Republican elected officials were (and still are) in a bind: the primary system, with its low turnout of the highly motivated, makes them vulnerable to pro-Trump forces, and they continue to face large internal collective action problems if they want to repudiate him. ${ }^{3}$ More cynically, many of them, and many of their large donors, were willing to put up with his hostility to free trade, immigration reform, and non-white voters, for the (now actualized) possibility that he would cooperate with them sufficiently well to create large tax cuts for the wealthy and corporations, especially given their assumption that he would be incompetent at creating trade barriers and significantly restricting immigration.

Under any other plausibly democratic electoral system, or absent the interference of foreign powers, or absent an arm of the civilian state, or, even given all those factors, if his opponent had made just slightly different strategic choices, Trump would have not have become President. He was in fact astonishingly lucky. Nevertheless, something clearly went terribly wrong for him to be in a position to come anywhere close to power. In November 2016, a large portion of the American electorate was sufficiently disengaged not to vote against him, and another substantial portion was sufficiently alienated, ill-willed, ignorant, deluded, or reckless to indeed vote for him.

Trump's emergence was enabled by numerous factors that have toxified American politics over several decades, and for which both parties bear some responsibility. Among these factors is what we might call the partisanisation of politics. In Congress, cross party-line voting has declined from a point in the 1950's in which a significant minority of Democrats voted with the majority of Republicans more often than several Republicans, and vice versa, to a point in which none do, and there is very little overlap on divisive issues. Although, in the country as a whole, the national vote is fairly evenly split, with Democrats normally getting a small majority in aggregated national votes, counties are increasingly either solidly Republican or solidly Democratic; when people move, they tend to move to places where their political affiliations are widely shared. Alarmingly, while racial, religious and cultural tolerance have all increased markedly over the past 50 years, tolerance of supporters of the opposing party has declined dramatically. A poll asking adults whether they would be 'disturbed' if their child married a member of the opposing political party in 1960 found that fewer than 5\% of supporters of either party would be; in a similar poll in 2010, 33\% of Democrats and 40\% of Republicans answered 'yes' to the question.

\section{How Should Civic Educators Respond to the Situation?}

Civic education in schools should teach the knowledge, skills, attitudes and dispositions needed for competent citizenship. Exactly what those knowledge, skills, attitudes and dispositions are, depends on numerous contextual 
factors. Some concern the historical situatedness of the citizen (Germans and Americans need different knowledge), some concern the design of institutions (the kind of discernment needed in a proportional representation system with party lists is different from that needed in a system with very weak parties), and some concern the short-to-medium term trajectory of the polity.

Concerning this last variable, I want to put one possibility aside. Some may think that Trump's election and the behaviour of his administration constitute so serious a threat to liberal democratic norms and processes that the right way to engage in politics has radically changed and that normal engagement is inappropriate. At this point, they might think, the right way to engage is with hostility, distrust, and, when effective, force. Personally, I think that's a mistaken reading of the situation. There are, indeed, serious dangers; if nuclear war were triggered by his actions, liberal democracy would be no more. But the first year of the Trump administration suggests to me that, although his policies are harmful and his appointments, taken as a whole, are at best suboptimal, and although institutions such as the foreign policy apparatus are sustaining some real damage, existing liberal democratic institutions and norms are sufficiently robust to survive the current President. I may be wrong about that, but the significance of what I have to say here depends on that assumption.

If I'm right, then civic educators should continue to aim at producing the knowledge, skills, attitudes and dispositions that are needed to engage effectively and responsibly within the American political system. Of course, they need to teach students how existing democratic institutions work, and what have historically been effective ways of engaging in democratic politics, as well as some understanding of the history of the institutions they inhabit. Much of what civic educators already regard as their job remains intact. But I think more is needed. I shall offer a rough sketch of what I think the most urgent of those are, and finish first by noting a problem that schools face in facilitating success in civic education and then by raising a very practical difficulty that skilled, knowledgeable and well-willed teachers face.

\subsection{Online Media Literacy}

The first and most obvious thing students need to learn is online media literacy. Commentators sometimes romanticize the past, when 3 or $4 \mathrm{TV}$ and Radio networks, a couple of newspapers with national reach, and highly localized newspapers governed most access to news. Then in an oligopolistic market, and with relatively few news sources, competent citizens needed to be alert to what information they might not be getting, and how shared assumptions among elite journalists at the national level might be misshaping the news and public opinion. But, in the light of present experience, we can say, looking back, that journalists by and large adhered to reasonable standards of evidence and that for several decades, a professional tradition of investigative reporting ensured that at least some bona fide scandals would be reported, and the public would, if slowly, respond.

Online media literacy is very different. We are confronted by a deluge of information, it is immensely difficult to assess the reliability of the myriad of sources, we know we have a tendency to attend to and believe reports that confirm our own prejudices, and absent forceful and enforced regulation algorithms will operate in ways that feed, rather than interrupt, this tendency. We thus need to make special efforts to encounter ideas and information that challenge our prejudices, and make special efforts to make informed judgments about the sources on which we depend.

Saying much about exactly how teachers go about developing the necessary skills in their students is beyond the scope of this essay and beyond my competence. However, guiding them to normally-reliable sources must be part of the story. This may, in practice, be enormously difficult in a partisanised environment: observing that Breitbart and Fox News and the Rush Limbaugh show are not normally reliable sources, whereas the New York Times and the British Broadcasting Corporation normally are, may itself be considered as a partisan act: and families who consult Breitbart, Fox and Limbaugh are sufficiently numerous and sufficiently powerful to be able to cause serious trouble for some schools. Developing a critical attitude toward information must also be part of the story: teaching students how to scrutinize the sources of their information and to guard against their own tendency to be gullible, without developing an arrogance that inclines us to embrace our own prejudices. ${ }^{4}$

\subsection{Statistical Literacy}

A part of media literacy, but something which is independently important that competent citizens must be able to exercise, is statistical literacy. The whole of the mathematics curriculum in US secondary schooling aims at calculus as the pinnacle, and 'Statistics' is often viewed as a class for the mathematically challenged student. But, not only as citizens, but as consumers and increasingly as workers, we are assaulted with claims about what we should do that are grounded, in turn, in statistical claims. Advocates of any given policy will typically claim that it will only have good effects, and that it is bound to have them; opponents will typically claim the reverse. But in fact, most policies have some good and some bad effects and, when assessing any policy proposal, one can only make probabilistic judgments about the balance of costs and benefits. Orienting more of mathematics teaching toward understanding probabilities and statistical claims, and ensuring that students have practice in applying the knowledge and skills they develop to claims about policy, 
is probably an essential part of developing the relevant statistical literacy. Just as most citizens, most of the time, are not going to carefully scrutinize news media reports in detail, they are not likely to investigate statistical claims that lie behind claims about policy: to expect otherwise is to demand too much of the polity. But a well-functioning democracy requires that there is a substantial pool of ability to engage well in the critical consumption of statistical evidence and to scrutinize news media critically, and that this pool is well-distributed across the population: that is, that the pool should not mainly be concentrated at one end of the political spectrum, or in one part of the country, or in one social class.

\subsection{Critical Deference}

While it is important that the ability to engage critically with statistical and other evidentiary claims is distributed across the population, it is unrealistic to expect that most citizens will base most of their judgments about complex empirical matters bearing on policy, on a careful assessment of the scientific evidence. Democracies in modern, complex, industrial societies enact a division of labour: Nobody is expected to be an expert, or even competent, in everything, and everyone has to take a great deal of what is claimed on trust. The question for citizens is whom to trust, and on what basis to allocate that trust. Take a simple example: climate science. Very few - in fact hardly any - citizens are equipped with the expertise necessary to evaluate the scientific evidence regarding climate change and its causes. The scientific consensus is that the planet is warming, and that human activity plays a significant, and remediable, role in causing that warming. Almost everybody who believes the same thing does so because they trust scientists when they form a consensus, not because they have, themselves, explored the evidence. The same is true of people who believe that MMR vaccines are safe enough, that the costs of disease in a nonimmunized population is high enough, and that the government should ensure high rates of vaccination. But can scientists be trusted, and if so, which ones?

Curiously, in both the examples I have given, those who go against the scientific consensus tend not to say that scientists can't be trusted generally, but that those scientists can't be trusted. The climate change denial industry went to great lengths to find, and publicize the opinions of, scientists (usually scientists lacking relevant expertise) who went against the consensus; and the anti-vaccine movement relies heavily on the (now-known-to-befraudulent) results of a (now-discredited) medical researcher. There is, in fact, consensus among scientists with relevant expertise on both those issues. But sometimes scientists are wrong, even when those with relevant expertise have a consensus (for example, for many years nutritionists claimed, on the basis of low quality studies, that fat, rather than sugar, was the central dietary cause of heart disease). And scientists - like experts generally - commonly pronounce on issues concerning which they, in fact, have no relevant expertise: for example, doctors frequently comment on the morality of abortion, about which they have no more expertise than a motor mechanic about whether automobile engines have souls. The development of the abilities to know when it is reasonable to defer to experts, to discern which experts to defer to, and to discern who has expertise in what, are vital for democratic competence.

\subsection{Ability to Give and Take Reasons and Maintain Respect for Those With Whom We Disagree}

The abilities to give and take reasons in a discursive context and to disagree respectfully are vital for healthy personal relationships, essential in most workplaces and an important part of democratic competence. Their value for democratic competence faces two ways.

As a citizen I have a right to give my own input into the deliberative process. To do that, I have to be able to give reasons, and be able to give them in ways that can be heard by at least some of those who have not, previously shared them, so that they can reflect on them and be influenced by them; if I cannot give them, or can only give them in ways that lack the potential to influence others, then I do not really have a role in the deliberation. Conditions that disenable people from considering reasons are quite varied. If I am inarticulate, most others cannot consider my reasons; but if I am articulate, but manifestly contemptuous, many others cannot consider them; conversely, if they are contemptuous of me, and sometimes if they are unduly in awe of me, this disables them from hearing me. So not only appropriate knowledge and skills, but also appropriate attitudes and dispositions, are needed for deliberation to be rich, inclusive, and effective. Just to be clear, the condition 'so that they can reflect on them and be influenced by them' can be fulfilled without my reasons actually being adopted, or becoming shared by others. If my reasons are bad reasons then, perhaps, all others who hear them will, on reflection, reject them (and, at least if they are bad enough reasons, that is to be welcomed!). The point is just that my way of giving the reasons must be such as to trigger the possibility of reflection.

The corollary of the right to give reasons is the obligation to take reasons as well. When others give their reasons, I have a duty to hear them, and to at least consider reflecting on them in such a way that they might end up influencing me. My duty to my fellow denizens, by virtue of sharing a polity with them, is not to reflect on every reason I hear, and certainly not to do so every time I hear it, but to consider, rather than to dismiss, novel reasons when they are offered.

The relevant skills, dispositions, and attitudes are difficult to learn, both because the broader political culture does not model them, and because much schooling involves just taking, and not giving, reasons. The 
Mathematics teacher is an authority on mathematics, the History teacher is an authority on history, and students can become unduly accustomed to seeing the teacher as an authority when it comes to reasons. Anecdotally, I find when I teach first year students fresh from high school at a very selective public university in the Midwest, that they are not just unfamiliar with, but very apprehensive about, the practice of giving and taking reasons in a discursive setting. Some students are skilled at giving reasons, others are skilled at taking them, but most are skilled in neither and few are skilled in both.

Respecting some of those with whom we disagree underpins the ability and inclination to give and take reasons. If we do not respect those with whom we disagree, we will not feel that we owe them reasons: simply winning, will suffice. And if we do not respect them, it is difficult for us to give their reasons serious consideration. There is no need to respect all with whom we disagree; like some of those with whom we agree, some of those with whom we disagree may not be worthy of our respect. And we need not respect the particular person with whom we are disagreeing at the moment; it is often enough to know that we respect others who hold their view.

A final comment about reason-giving and reasontaking. Some people have unreasonable views, and some refuse to abide by the basic norms of giving and taking reasons: indeed, the President is a remarkable example of this; he blusters, he does not listen, he lies and he bullshits (in the technical sense of being indifferent to the truth or falsity of his utterances). ${ }^{5}$ Exactly how to deal with such people is, itself, something about which reasonable people can disagree, and learning how to identify them is itself a skill. The good faith reason-giver-and-taker runs the risk of marginalizing the inarticulate, if she is too ready to attribute malpractice to others, but runs the risks of allowing the mal-practitioner to marginalize others if she is too charitable. Learning to be a good giver and taker of reasons is real work.

\section{Challenges}

If I am right about the urgency of these tasks, schools especially secondary schools - will face large challenges. I mention just one here, which is structural. Whereas mathematics, foreign languages, and physical education, can be taught in discrete, somewhat siloed, classes, what I have called for cannot be achieved through a single department or a single class. The knowledge and skills needed probably have to be taught across the curriculum; media literacy, mathematics, history, and economics are all involved, and may not be easily contained in a single academic department. Yet secondary schools are, typically (and not only in the US) organized in a siloed manner by departments; fostering curricular and instructional cooperation across departments is difficult in the very best secondary schools (fostering it within departments is a challenge even in moderately good schools). Seriousness about civic education requires attention from leaders and administrators who are already, often, overstretched by other demands. ${ }^{6}$

Now put aside that structural problem. Teaching the ability to give and take reasons and to connect and debate respectfully across difference requires, among other things, modelling. This gives rise to three challenges.

The first challenge is simple. In a highly partisanised political culture, few such models are readily available; they do not occur 'naturally' in the broader environment the students inhabit; at best, they must seek out public television and radio, and highly moderated websites designed for this purpose. Indeed, exactly the reverse is modelled widely; disrespect, name-calling, misrepresentation, and straightforward dissembling. The teacher has no option but to seek out models to expose the students to and model the virtues themselves. Exactly what this requires of the teacher - exactly what traits to inculcate in herself and what behaviours to exhibit - probably varies by context and, in any case, is not always obvious. Civic educators have to address this collectively, and individual civic educators have to address it individually, regardless of whether the profession does.

The second challenge is that schools inevitably, and to a considerable extent, reflect the culture of the broader society. Good leadership at the school and district level always combats this tendency, but always does so with only limited success. If the society is highly partisanised, then the school itself will be at least somewhat partisanised. Teaching is not a highly mobile profession - many teachers grew up within a short distance of the school that employs them, and most teachers are from the state in which they teach. At best geographic polarization - the tendency of people to live among others who share their broad political loyalties - will infect the school, and at worst, the school will be just another location for partisanship, with teachers who generally agree about politics, and are insensitive to the desirability that other voices are heard respectfully. Even the standard academic subjects rely on a school environment that is not actively hostile to their learning goals, but civic education probably depends on a school environment that routinely reinforces the learning goals and embodies and models the dispositions and attitudes it calls for.

The final challenge is hinted at in the first few paragraphs of this essay. Teachers themselves must model the kinds of traits and habits students need to give and take reasons in discursive situations and to connect and debate respectfully across disagreement. There is a reasonable debate about whether they are required to withhold their own views in order to do this effectively, or whether it is also possible disclose one's views. ${ }^{7}$ I am very sceptical that it is possible for them to do so while expressing strong 
negative views about the 'other' side. Throughout most of all previous Presidencies in my adulthood, it was possible for a teacher to talk respectfully about the sitting President without thereby being undignified or deceitful. Throughout their entire terms in office it was reasonable to respect Presidents Carter, Reagan, G.H.W. Bush, G.W. Bush, and Obama, and through most of Clinton's presidency, it was reasonable to respect him. The challenge is simple: the age of Trump is the age of Trump, someone it is reasonable perhaps to like and perhaps to pity, but not to respect. And talking as if one respects him is not consistent with conveying the value of the traits that competent citizens have: actually to respect this President would be possible only if one did not value the package of knowledge, skills, attitudes and dispositions that are essential for competent citizenship.

I do not think this challenge is lessened by the fact that most politicians across the political spectrum themselves have no respect for the President. It is true that even many of his political supporters in national-level elected office and many of his Cabinet and staff appear not to respect him; and the majority of national-level elected officials in his party do not even appear to be supporters. But in the classroom, working with students whose parents voted for Trump and who, themselves, may have campaigned for or, if they are old enough, voted for him, expressions of disrespect for the President will sometimes convey disrespect for them and their families, on political grounds. Even if it were appropriate for the teacher-as-citizen to convey disrespect for those students and their families, for the teacher-as-teacher, appearing to disrespect them makes the job of turning them into competent citizens even harder than it already is, and may even make it more difficult to turn the students who agree with the teacher into competent citizens. Yet, for the teacher, even appearing to respect the current President is not compatible with conveying the value of the actual components of democratic competence.

I do not have a solution to this challenge. Although my own teaching is, also, oriented towards, among other things, enhancing the competence of the students as citizens, I can choose what I teach, and teach issues which, while they are contentious across the partisan divide, do not require commentary on the views or actions of current elected politicians. Furthermore, my students are adults, of a sort, who have all met certain academic standards; and so are able to keep on topic (more or less). Like any teachers, while withholding my broad political views and my views about the issues I teach about, I do sometimes make comments, or sometimes jokes, about issues in the news, but it is easy for me to avoid commenting on the Presidency. ${ }^{8}$ Civic educators in secondary schools in particular do not have the luxuries I enjoy. For them, the challenge is much greater, and I cannot offer much in the way of help.

\section{References}

Frankfurt, H. (2005). On bullshit. Princeton University Press.

Hess, D. \& McAvoy, P. (2015). The political classroom. Routledge.

\section{Recommended Citation}

Brighouse, H. (2018). Civic education in the age of Trump. On Education. Journal for Research and Debate, 1(1). https://doi.org/10.17899/on_ed.2018.1.2

\section{About the Author}

Harry Brighouse is Bascom Dickson Professor of the Humanities, Professor of Philosophy, Affiliate Professor of Educational Policy Studies, and Director of the Center for Ethics and Education at University of Wisconsin-Madison.

\footnotetext{
${ }^{1}$ Thanks to Tim Brighouse, Madeline Brighouse Glueck, David O’Brien, Lynn Glueck, Emma Prendergast, and Gina Schouten for discussions and comments.

${ }^{2}$ To be clear: the design of the Electoral College influences how and where candidates campaign. In a direct election, the candidates would have behaved differently and we do not know how many votes each candidate would have received. But a two million margin is large enough, so that it is reasonable to think that it is probable (though not certain) that Clinton would have won in a straight vote.

${ }^{3}$ The experience of the 2017 special election for the US Senate in Alabama is instructive here: the primary selected a very right-wing candidate, despite the presence of an incumbent normally right-wing candidate, and although the selected candidate lost to a Democrat, he garnered a large vote in the face of serious and plausible accusations of sexual misconduct with girls below the age of consent.

${ }^{4}$ Emma Prendergast suggested that Wikipedia is a useful resource for teachers in this context: getting students to observe and, perhaps, engage in the process of discussion within the Wikipedia community about what constitutes a reliable source, and what claims, exactly, need sourcing, would at least provide a model for them of what an epistemically responsible community looks like and how it conducts its business.
} 
${ }^{5}$ See: Frankfurt (2005).

${ }^{6}$ Admittedly, some of these demands are less urgent - it really does not matter whether the basketball or football games are attended by the public. But, given the work it would take to divest themselves of these demands, even administrators who care about the right learning goals are stuck in a suboptimal equilibrium.

${ }^{7}$ See the excellent discussion in Diana Hess and Paula McAvoy (2015).

${ }^{8} \mathrm{I}$ have, though, trained myself not to joke casually, even in private among family and friends, about the President and his character or unsuitability for office, specifically in order to guard against the possibility that I would, in an off-guard moment, do so in class. 